\title{
REVISTA \\ INTERDISCIPLINAR

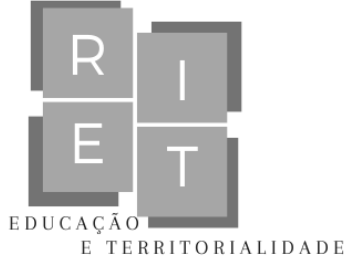 \\ O curso de arqueologia em São Gabriel da Cachoeira em tempos de pandemia (CESSG/UEA)
}

\author{
The archeology course in São Gabriel da Cachoeira in pandemic times \\ (CESSG/UEA)

\begin{abstract}
El curso de arqueología en São Gabriel da Cachoeira en tiempos de pandemia (CESSG/UEA)
\end{abstract}

\author{
Luciano Everton Costa Teles ${ }^{1}$ \\ Bacharelado em Arqueologia, Universidade do Estado do Amazonas (UEA) \\ São Gabriel da Cachoeira, Amazonas, Brasil \\ E-mail: lucianoeverton777@ hotmail.com \\ ORCID: https://orcid.org/0000-0001-6569-5606
}

\begin{abstract}
Resumo: a proposta presente nestas páginas consiste em expor como foi operacionalizado, pelo curso de bacharelado em Arqueologia da Universidade do Estado do Amazonas no município de São Gabriel da Cachoeira/AM, o desafio de retomar as atividades acadêmicas do semestre 2020/1 com metodologias não presenciais, em função do avanço da pandemia do novo Coronavírus na região. A ideia é que, a partir das experiências relatadas, possamos refletir sobre as novas tecnologias no processo de ensino em tempos de pandemia.
\end{abstract}

Palavras-chave: Ensino de Arqueologia; Pandemia; Novas Tecnologias, UEA.

Abstract: the proposal present in these pages consists of exposing how the baccalaureate course in Archeology at the State University of Amazonas in the municipality of São Gabriel da Cachoeira / AM was made operational, the challenge of resuming academic activities in the 2020/1 semester with non-face-to-face methodologies, due to the advance of the new coronavirus pandemic in the region. The idea is that, based on the experiences reported, we can reflect on the new technologies in the teaching process in times of pandemic.

Keywords: History teaching; Pandemic; New Technologies, UEA.

Resumen: la propuesta que se presenta en estas páginas consistem en exponer cómo se puso en funcionamiento el bachillerato en Arqueología de la Universidad Estadual de Amazonas en el municipio de São Gabriel da Cachoeira / AM, el desafío de retomar las actividades académicas en el semestre 2020/1 con no- Metodologías presenciales, debido al avance de la nueva pandemia de coronavirus en la región. La idea es que, a partir de las experiencias reportadas, podamos reflexionar sobre las nuevas tecnologías en el proceso de enseñanza en tiempos de pandemia.

Palabras clave: Enseñanza de la arqueología; Pandemia; Nuevas Tecnologías, UEA.

Data de recebimento: 14/04/2021

\footnotetext{
${ }^{1}$ Doutor em História pela Universidade Federal do Rio Grande do Sul. Professor Adjunto da Universidade do Estado do Amazonas/CEST. Coordenador do curso de Bacharelado em Arqueologia ofertado em São Gabriel da Cachoeira. E-mail: lcteles@uea.edu.br

RIET- ISSN 2676-0355, Dourados, v. 2, n. 2, p. 343 a 353, jan./jan., 2021 


\section{O curso de arqueologia em São Gabriel da Cachoeira em tempos de pandemia (CESSG/UEA)}

Data de aprovação: 10/06/2021

DOI: $10.30612 /$ riet.v\%vi\%i.14552

\section{Considerações iniciais}

No dia 17 de março de 2020 a administração superior da Universidade do Estado do Amazonas instituiu um Grupo de Gestão (GG - Grupo de Gestão de Contingência da UEA Diante da Pandemia causada pelo SARS-Cov-2, o GG - UEA COVID-19) ${ }^{2}$ para acompanhar a situação epidemiológica no estado do Amazonas e, a partir disso, avaliar a possibilidade de retomar as atividades acadêmicas do semestre 2020/1 que haviam sido suspensas no dia 16 de março em função do avanço do novo Coronavírus na região.

O Grupo avaliou que alunos e professores da Instituição deveriam permanecer em casa, mantendo todos os cuidados indispensáveis para se protegerem do vírus e não se infectarem. A direção e os administrativos continuariam desenvolvendo as suas atividades, porém em sistema de rodízio e mantendo o distanciamento social e as medidas de proteção - uso de máscaras e álcool em gel.

Com o significativo avanço da pandemia no Amazonas, ratificada pelo Grupo Gestor da COVID-19 da UEA, o trabalho em casa, home office, foi instituído na Universidade, assim como foi sugerido por este ao Conselho Acadêmico (CONSUNIV) que o calendário acadêmico fosse reestruturado e que uma nota técnica fosse emitida, indicando os parâmetros legais e as diretrizes a serem observadas para o retorno das atividades do semestre 2020/1, de forma remota.

A proposta deste artigo é expor como o desafio de retomar as atividades acadêmicas com metodologias não presenciais foi encarado pelo curso de bacharelado em Arqueologia no município de São Gabriel da Cachoeira. A ideia é que, a partir das experiências relatadas, possamos refletir sobre as novas tecnologias no processo de ensino em tempos de pandemia.

\section{O contexto da pandemia e o curso de Arqueologia do CESSG/UEA}

A Universidade do Estado do Amazonas tem como um dos seus pilares de expansão a interiorização. Nesse caminho, ela tem assegurado a sua presença em diversos municípios do Amazonas, ofertando cursos presenciais - no formato modular - e não presenciais mediado por tecnologias - em praticamente todo o Amazonas.

Na figura abaixo podemos ter a dimensão da sua presença no Amazonas:

${ }^{2}$ O GG - UEA CIVID-19 foi instituído pela Portaria GR/UEA n. 0205 de 16 de março de 2020.

RIET-ISSN 2676-0355, Dourados, v. 2, n. 2, p. 343 a 353, jan./jan., 2021 


\section{O curso de arqueologia em São Gabriel da Cachoeira em tempos de pandemia (CESSG/UEA)}

Figura 1. Mapa do Amazonas/Localização do município de São Gabriel da Cachoeira (na região conhecida como "cabeça do cachorro").

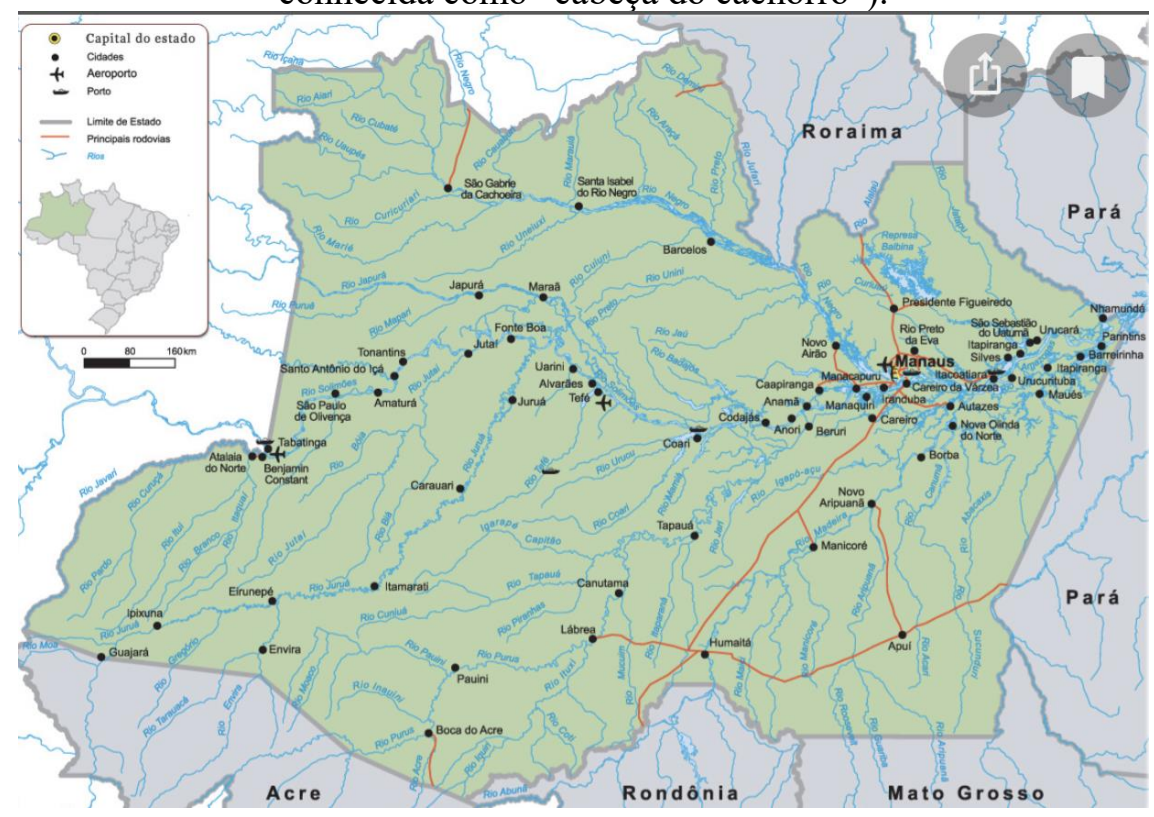

Fonte: https://br.pinterest.com/pin/346284658846895981/. Acesso em 13/04/2021.

No alto rio Negro, especificamente no município de São Gabriel da Cachoeira, a UEA possui um Centro de Estudos Superiores $^{3}$ no qual oferta cursos na modalidade modular ${ }^{4}$. O curso de bacharelado em Arqueologia foi implantado no segundo semestre de 2018 tendo como justificativa principal a riqueza de registros arqueológicos existentes na localidade e também a falta de profissionais da área para estudá- $\operatorname{los}^{5}$.

No contexto da pandemia e atendendo a solicitação do Grupo Gestor da UEA, o Conselho Universitário (CONSUNIV) reprogramou o calendário acadêmico e a Pró-Reitoria de Graduação (PROGRAD) emitiu uma nota técnica sobre o retorno das atividades acadêmicas.

A Nota Técnica 01/2020 PROGRAD/UEA tinha como finalidade:

fundamentar a reorganização das atividades acadêmicas por ocasião do retorno das aulas após 138 dias de suspensão (...) em decorrência da pandemia do COVID-19, constituindo-se em orientações necessárias ao

\footnotetext{
${ }^{3}$ O Centro de Estudos Superiores de São Gabriel da Cachoeira (CESSG).

${ }^{4}$ Dentre os cursos ofertados temos os tecnológicos (Alimentos, Gestão Ambiental, Gestão Comercial, Logística e Tecnologia em Gestão de Turismo), as licenciaturas (Ciências Biológicas, Educação Física, Matemática, Pedagogia Intercultural Indígena e Química) e bacharelado (Saúde Coletiva e Arqueologia).

${ }^{5}$ Projeto Pedagógico do Curso de Arqueologia (2018).
}

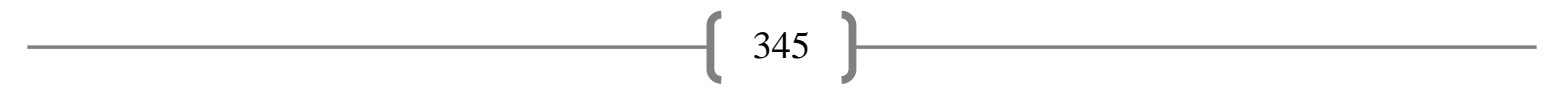

RIET- ISSN 2676-0355, Dourados, v. 2, n. 2, p. 343 a 353, jan./jan., 2021 


\section{O curso de arqueologia em São Gabriel da Cachoeira em tempos de pandemia (CESSG/UEA)}

planejamento acadêmico dos componentes curriculares dentro de seus cursos (p. 1).

A Nota instituiu a possibilidade de continuar o semestre remotamente, porém considerando a realidade regional dos municípios do interior, o curso de Arqueologia, com base na respectiva Nota, elaborou um plano de retorno nos seguintes termos:

O curso de bacharelado em Arqueologia ofertado no Centro de Estudos Superiores de São Gabriel da Cachoeira, porém vinculado ao Centro de Estudos Superiores de Tefé, sob a coordenação do professor Dr. Luciano Everton Costa Teles, retomará as suas atividades acadêmicas tendo como base a Nota Técnica 01/2020 PROGRAD/UEA. (...)

Nesse sentido, considerando a possibilidade de cômputo de atividades não presenciais para fins de cumprimento do semestre e da carga horária das respectivas disciplinas ofertadas (Nota Técnica, p. 1 e p. 7), o curso de Arqueologia, sempre tendo como finalidade atender a todos os alunos regularmente matriculados, utilizando para isso de metodologias não presenciais diversas - com uso ou não da internet - e da ação articulada com a direção e o secretário da unidade na qual o curso ocorre, seguirá os seguintes passos para a sua retomada acadêmica:

1. Emprego de metodologias não presenciais em plataformas como AVA/UEA e/ou Google Classroom, especialmente o Google Meet;

2. Utilização de planos de estudo para atividades não presenciais, principalmente para aqueles que não possuem equipamentos e/ou acesso à internet;

3. Ofertas de disciplinas com apenas cargas teóricas (em anexo o cronograma das disciplinas conforme o calendário acadêmico 2020/1);

4. Criação de grupos de WhatsApp para facilitar a comunicação entre os professores e os alunos de suas respectivas disciplinas;

5. De forma articulada, o uso de Facebook e blogs para também disponibilizar materiais e fomentar debates no âmbito das disciplinas;

6. Elaboração de planos de disciplina com o detalhamento das metodologias não presenciais que serão utilizadas;

7. Em diálogo com a direção do Centro, estabelecer agendamentos e rodízios de alunos para o acesso às dependências do prédio, como laboratórios, biblioteca, secretaria, auditório, etc.;

8. Reforçar os cuidados necessários para se proteger da COVID-19, sobretudo evitando aglomerações, lavando as mãos e usando máscaras.

A coordenação do curso acompanhará todo o processo, em diálogo com os professores, os alunos e a direção da unidade onde o curso é ofertado, colocando-se como mediadora nesse processo dentro do contexto de ensino atual em tempos de COVID-19, procurando seguir todas as diretrizes traçadas pelos documentos legais constituídos no âmbito da Administração Superior da Universidade (CIRCULAR 1/2020, p. 1-2).

RIET- ISSN 2676-0355, Dourados, v. 2, n. 2, p. 343 a 353, jan./jan., 2021 


\section{O curso de arqueologia em São Gabriel da Cachoeira em tempos de pandemia (CESSG/UEA)}

Como é possível verificar, o curso de Arqueologia pautou o seu retorno tendo como base as disciplinas de caráter teórico e o uso de metodologias não presenciais, as mais variadas possíveis. Não obstante, com o intuito de inserir nesse movimento a totalidade dos alunos do curso e tendo consciência da precariedade de acesso à internet no município, planos de estudos físicos foram elaborados e enviados (via barco e/ou avião) para serem entregues aos alunos nas suas comunidades e sítios.

Além disso, a Universidade do Estado do Amazonas lançou uma ação pela PróReitoria de Extensão e Assuntos Comunitários (PROEX) com vistas a fornecer chips com dados móveis para aqueles alunos que até possuíam o equipamento de celular ${ }^{6}$, porém não tinham como comprar planos de internet para participar das atividades disciplinares.

É importante sublinhar que as novas tecnologias - notebooks, tablets, celulares, smart tv's e as plataformas digitais contidas neles, além da investigação em sites de centros e instituições de pesquisa, etc. - possibilitam em grande medida o acesso às novas linguagens (audiovisual, podcast, etc.), sobretudo no mundo de hoje que disseminou um aparato tecnológico expressivo cujo maior exemplo é o aparelho de celular, no qual muitos têm acesso (os que podem, uma vez que há desigualdades de obtenção e exclusão digital) e conseguem na palma da mão ter contato com as mais variadas informações, das simples notícias às análises mais complexas.

Nesse sentido, não há como num mundo globalizado e digital, no interior do qual as crianças já crescem com um dedinho no celular, manipulando-o, ter um espaço de formação profissional sem incorporar essas tecnologias criadas pela humanidade e as novas linguagens que emergem como propostas para um ensino até mesmo inovador ${ }^{7}$. Na universidade, onde o compromisso com a formação acadêmica e profissional é algo constante e presente, integrar ao ensino as novas linguagens e tecnologias é tanto fundante quanto necessário.

\section{O desafio no curso de Arqueologia: continuidade do semestre 2020/1}

A Instituição, como fica evidente na Nota Técnica e na Circular do curso de Arqueologia, preocupou-se em propiciar a todos os acadêmicos a participação de modo não presencial no semestre 2020/1. Nesse momento, o desafio estava posto.

\footnotetext{
${ }^{6}$ Salientamos que existiam alunos sem o equipamento de celular e mesmo os que o possuíam, o aparelho estava obsoleto.

${ }^{7} \mathrm{O}$ entendimento é que "as transformações educacionais devem ser encaradas dentro do contexto mais amplo do impacto das NTICs sobre a sociedade e, também, do ponto de vista da aprendizagem" (SILVA, 2012, p. 4).
}

RIET- ISSN 2676-0355, Dourados, v. 2, n. 2, p. 343 a 353, jan./jan., 2021 


\section{O curso de arqueologia em São Gabriel da Cachoeira em tempos de pandemia (CESSG/UEA)}

Pouco antes de reiniciar o semestre, a direção do Centro de Estudos Superiores de São Gabriel da Cachoeira fez um levantamento/mapeamento das condições sociais e tecnológicas dos acadêmicos do curso de Arqueologia, visando incluí-los digitalmente e também identificar quem precisaria do plano de estudo impresso ${ }^{8}$.

Por outro lado, estabelecemos uma conversa com os professores do curso, apresentando a eles os documentos legais que iriam nortear o nosso retorno remoto. Eles tiveram então que reformular e redirecionar os seus respectivos planos das disciplinas, incluindo obrigatoriamente agora o uso de metodologias não presenciais para levar adiante o término do semestre 2020/1. Nesse contexto de pandemia, eles não estavam sozinhos nessa empreitada, pois professores de diversas instituições de ensino foram instigados a seguir nesse mesmo percurso (SILVA FILHO, 2020; OLIVEIRA, 2020).

Como dissemos, neste texto vamos nos deter na prática pedagógica desenvolvida e vivenciada no curso de Arqueologia, considerando duas disciplinas como exemplo: Arqueologia da Amazônia 2 e Arqueologia Forense, Ética e Direito Arqueológico?.

A primeira ação consistiu em enviar ao grupo de WhatsApp dos alunos do curso a Circular 01/2021 e o planejamento do retorno das aulas de forma remota. Explicamos ainda que empregaríamos o WhatsApp para criar grupos/disciplinas, ou seja, para cada disciplina a ser ministrada teríamos um grupo específico no aplicativo. Isto pelo fato de que a única plataforma possível de viabilizar as aulas seria através de WhatsApp, dada a precariedade da internet no município de São Gabriel da Cachoeira ${ }^{10}$ e também pelo fato de que a maioria dos alunos possuía celular.

Desse modo, nos grupos das respectivas disciplinas, os alunos entraram e lá puderam dar seguimento as atividades de ensino planejadas. Neles eles participavam de debates sobre os textos (através de áudio ou escrevendo as suas impressões e leituras críticas), assistiam as videoaulas e/ou audioaulas, assim como palestras e documentários (disponíveis no YouTube, por exemplo), tiravam as suas dúvidas sobre os assuntos tratados nas aulas e, claro, entregavam os trabalhos solicitados pelo professor. Na dinâmica de todo esse processo, o papel do professor como mediador e debatedor se colocou como trivial, pois era

\footnotetext{
${ }^{8}$ Isto foi feito através do google formulário e também com a ajuda dos próprios acadêmicos do curso.

${ }^{9}$ A primeira disciplina foi ministrada pelo professor doutor Leno José Barata Souza. Já a segunda pelo professor doutor André de Oliveira Melo.

${ }^{10}$ Em São Gabriel da Cachoeira nem o Google Classroom e nem o Ambiente Virtual de Aprendizagem (AVA/UEA), conseguiram ser acessados.
}

RIET- ISSN 2676-0355, Dourados, v. 2, n. 2, p. 343 a 353, jan./jan., 2021 


\section{O curso de arqueologia em São Gabriel da Cachoeira em tempos de pandemia (CESSG/UEA)}

ele o grande incentivador (com perguntas a serem respondidas, trechos de textos a serem explorados, etc.) da participação dos discentes nos grupos.

Nesse sentido, a primeira dimensão a considerar dessa experiência diz respeito à integração do WhatsApp ao processo de ensino, tornando-se a base indispensável para a realização das aulas. Por intermédio deles foi possível entregar aos alunos os textos em PDF das disciplinas, as audioaulas, os documentários e as palestras. Para melhor explanação do “experimento", vamos enumerá-los abaixo:

\section{Os textos em PDF e as audioaulas}

Considerando as duas disciplinas como exemplos, nos grupos de WhatsApp foram disponibilizados, num primeiro momento, os planos das disciplinas reformulados e uma planilha denominada "matriz de design instrucional", na qual todas as atividades das disciplinas - textos, documentários, atividades avaliativas, entre outros - estavam informadas. Junto com a matriz também foi encaminhado aos alunos um "roteiro de estudos", que continha o prazo para as leituras dos materiais oferecidos e as datas das avaliações, conforme exemplos abaixo:

Arqueologia da Amazônia II - Ementa

Grupos ceramistas, complexos ceramistas e seus significados socioculturais dos primeiros ceramistas aos cacicados. Os conceitos horizonte, tradição, fase, estilo, tecnologia e territorialização. Padrões tecno-estilísticos, padrões de assentamento e padrões funerários. Os casos Marajó e Santarém. Os geoglífos do Acre e os megalitos do Amapá. As tradições cerâmicas da Amazônia. Fluxo, guerra e interação social: o papel das redes de troca na formação das sociedades complexas.

(...)

Roteiro de estudos - Arqueologia Amazônica II

Aula 1 - 03/08, segunda-feira: CARNEIRO, Robert L. "A Base Ecológica dos Cacicados Amazônicos". Revista de Arqueologia 20, p. 117-154, 2007.

Live (Prêmio Luis Castro de Faria 2020, IPHAN): https://www.youtube.com/watch?v=aSwLMO93PnM\&t=38s

- Cada estudante enviar um vídeo ou áudio apresenando a si e seu tema de interesse e pesquisa.

Aula 2 - 04/08, terça-feira: Navegar no site e ler:

https://www.percursoseducacao.com.br/arqueologia

ROOSEVELT, Anna. 1992 "Arqueologia amazônica", in CARNEIRO da CUNHA, Manuela (org.), História dos índios do Brasil, São Paulo, Companhia das Letras/ Fapesp/SMC, pp. 53-86.

- Exercício: o que a arqueologia amazônica nos diz sobre os povos indígenas do passado e presente?

Aula 3 - 05/08, quarta-feira: Live (história antiga do Brasil)

RIET- ISSN 2676-0355, Dourados, v. 2, n. 2, p. 343 a 353, jan./jan., 2021 


\section{O curso de arqueologia em São Gabriel da Cachoeira em tempos de pandemia (CESSG/UEA)}

https://www.youtube.com/watch?v=v3Tgz6q97Q\&list=PLejNsiHd8u5IwptWSZxv4of5Ecw8JuQpC\&index=11

Neves E. G. (2015). Uma rede de fios milenares: um esboço da história antiga do rio Negro. Baré: povo do rio. São Paulo: Edições SESC, 42-59.

- Debate no grupo.

Aula 4 - 06/08, quinta-feira: Aula: Parinã e algumas questões da arqueologia em São Gabriel da Cachoeira

Meira, M., Velthem, L. H. V., Lima, H. P., Marques, F. T., Emperaire, L., \& de Alencar Guzmán, D. (2019). Povoamentos indígenas e assentamentos coloniais no Rio Negro: perspectivas de pesquisa colaborativa. $A R U$, Revista de pesquisa intercultural da bacia do Rio Negro n. 3, p-118... [e assim sucessivamente] (ROTEIRO DE ESTUDOS, 2020, p. 1).

Após esse primeiro passo, os professores das respectivas disciplinas providenciaram no grupo os textos em PDF e as audioaulas produzidas (gravadas e editadas pessoalmente). No primeiro caso, há inúmeros periódicos científicos da área de Arqueologia (e de outras também) que colocam à disposição, com acesso gratuito e livre, diversos artigos que podem ser trabalhados. Há também os repositórios de teses e dissertações que igualmente podem ser explorados para estudos. Com essa oportunidade, foi dessa ceara que os professores escolheram os textos em PDF e enviaram para o WhatsApp das turmas.

Por outro lado, as audioaulas foram elaboradas com base nos textos em PDF selecionados para serem discutidos, e foram pensadas para serem utilizadas pelo alunado paralelamente ao processo da leitura dos textos, com a vantagem de que elas facultam aos discentes escolher o melhor horário da internet em São Gabriel da Cachoeira para baixá-las e, da mesma forma, optar por um horário (dentro da sua realidade cotidiana) para ouvi-las.

Cabe sublinhar que a duração das audioaulas não podia ser longa. Ela tinha que girar em torno de no máximo 10 a 15 minutos e ser compactada para facilitar o acesso por parte dos alunos do curso (compactadas para serem baixadas por eles, por força da precariedade da internet no referido município).

\section{Os documentários e as palestras}

Como já mencionamos, a plataforma base para as aulas não presenciais foi o WhatsApp, o que abriu variadas perspectivas para além da exploração de textos em PDF e das audioaulas. Nessa esteira, com essa abertura proporcionada por ela, os professores colocaram nos grupos das turmas pequenos documentários sobre os assuntos a serem tratados nas disciplinas como, por exemplo, "Amazônia pré-colonial: arqueologia e conservação" (tema da disciplina Arqueologia da Amazônia 2). 


\section{O curso de arqueologia em São Gabriel da Cachoeira em tempos de pandemia (CESSG/UEA)}

Nesse mesmo propósito, foi possível lançarem mão de palestras de professores da área de Arqueologia. Em geral, buscaram, quando assim praticável, disponibilizar palestras de professores autores dos textos com os quais estavam trabalhando. A título de ilustração, temos a palestra da arqueóloga Cristiane Eugênia Amarante versando sobre o que é arqueologia forense (tema da disciplina Arqueologia Forense, Ética e Direito Arqueológico).

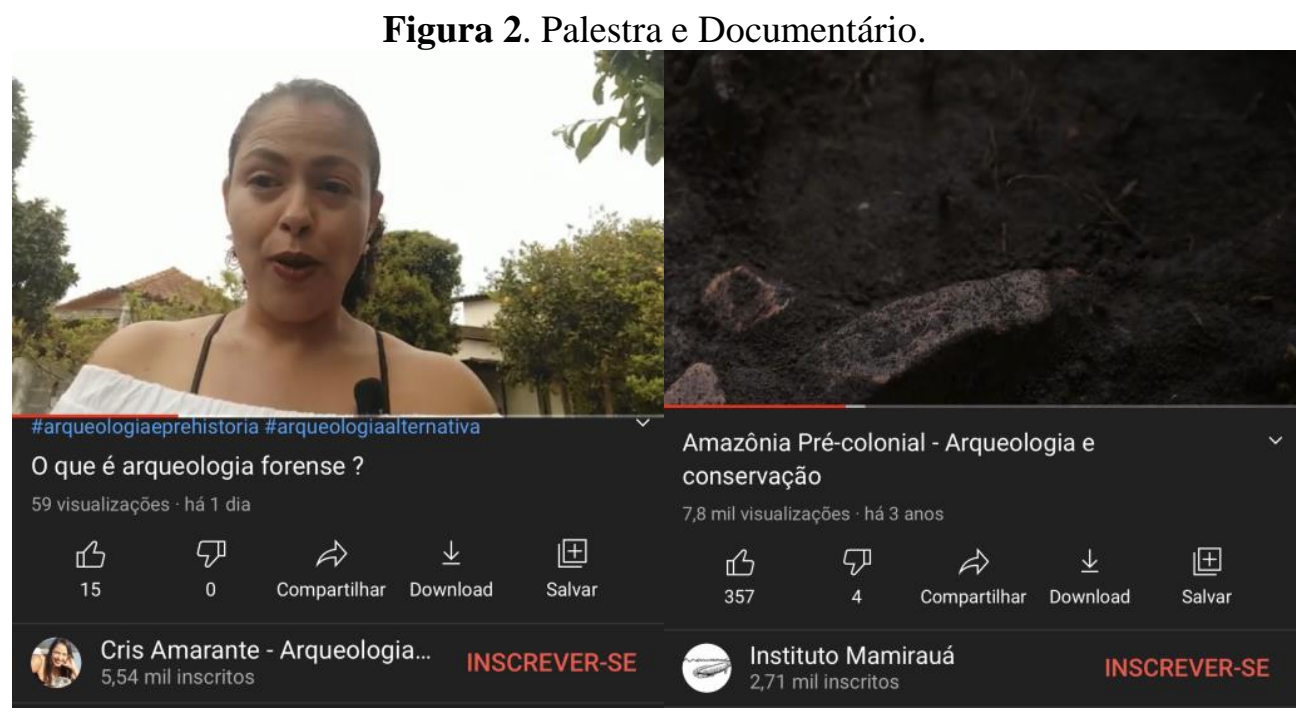

Fonte: acervo do autor (2021).

Os documentários e as palestras, ao lado dos textos em PDF e das audioaulas, contribuem significativamente no processo de ensino-aprendizagem não presencial. E podem ser averiguados/analisados inclusive nos termos de sua produção.

\section{O ofício do arqueólogo: registros arqueológicos, instrumental teórico e produção do} conhecimento arqueológico

Apesar de que as disciplinas com atividades práticas tenham sido suspensas/impossibilitadas dentro desse contexto de pandemia, a discussão e o debate acerca da produção do conhecimento arqueológico ocorreu. E ainda que não seja possível a escavação em sítios arqueológicos e a manipulação dos vestígios lá encontrados, os professores das disciplinas elencadas como exemplo não se furtaram em enviar para os alunos fotos e imagens de artefatos arqueológicos encontrados em sítios espalhados pela Amazônia com o objetivo de debater as interpretações elaboradas sobre eles. 


\section{O curso de arqueologia em São Gabriel da Cachoeira em tempos de pandemia (CESSG/UEA)}

Concomitantemente a alguns textos de conteúdo e de teoria no âmbito das duas disciplinas, tais artefatos arqueológicos foram lidos (com o auxílio das audioaulas) intentando promover o que foi indicado nos planos das disciplinas (e na matriz de design instrucional) como uma atividade avaliativa pautada nos elementos de produção do conhecimento arqueológico. Ou seja, a produção de uma análise tendo como base os registros arqueológicos, os textos propostos e trabalhados e o cabedal teórico de conhecimento de cada aluno adquirido ao longo do curso.

Isto porque pensamos (juntamente com os professores) que tal atividade contribui para que os futuros profissionais da área de Arqueologia possam especialmente elaborar uma "situação-problema, elencar indagações, levantar hipóteses, analisar o conteúdo da fonte, construir argumentos para a compreensão da realidade estudada, produzir sínteses conferindo significação ao conhecimento produzido" (URBAN e LUPORINI, 2015, p. 20).

Toda essa preocupação tem como finalidade o processo de formação inicial do profissional da área, que precisa necessariamente dominar os pressupostos da sua ciência. Esse aspecto é fundante e foi levado em conta nas aulas do curso de Arqueologia do CESSG/UEA.

\section{Considerações finais}

A pandemia do novo Coronavírus nos trouxe alguns desafios, entre eles a necessidade de estabelecer e manter o isolamento social, instituir as medidas de proteção ao vírus e de desenvolver vacinas. E o processo de isolamento social tornou inescusável o uso de metodologias não presenciais para que as aulas na educação superior (mas também na educação básica) continuassem ao longo do ano. Um desafio e tanto!

Porém, como procuramos demonstrar, o curso de Arqueologia da Universidade do Estado do Amazonas, unidade de São Gabriel da Cachoeira (CESSG), em concordância com a nota técnica emitida pela administração superior, deu continuidade ao semestre 2020/1 através do uso de tecnologias e de metodologias não presenciais que buscasse atingir a "totalidade" dos alunos, num esforço de inclusão digital (inclusive com entregas de chips com dados móveis) e, não sendo absoluto esse processo, de fazer chegar o material impresso até a casa/comunidade dos acadêmicos.

Por outro lado, os professores procuraram por todos os meios oportunizados elaborar as suas aulas e os seus conteúdos, o que particularmente tentamos expor (alguns fragmentos)

RIET- ISSN 2676-0355, Dourados, v. 2, n. 2, p. 343 a 353, jan./jan., 2021 


\section{O curso de arqueologia em São Gabriel da Cachoeira em tempos de pandemia (CESSG/UEA)}

aqui. A criatividade para superar as dificuldades e construir os conteúdos foi essencial. Muitas novidades surgiram nesse processo todo e que certamente serão integradas ao ensino presencial assim que este retornar.

\section{Referências}

CARDOSO, Ciro Flamarion. Uma Introdução à História. 5º ed. São Paulo: Brasiliense, 1992.

COSTA, Diogo Menezes. Arqueologia Histórica Amazônica: entre sínteses e perspectivas. Revista de Arqueologia, v. 30, n. 1, p. 154-174, 2017.

LIMA, Helena Pinto. Análises cerâmicas na arqueologia amazônica: contribuições da Amazônia Central a uma longa trajetória de discussões. Revista de Arqueologia, v. 28, n. 1, p. 3-29, 2015.

OLIVEIRA, Vitor Lins. O ofício do historiador nos tempos de pandemia do Coronavírus. XIX Encontro de História da ANPUH/RIO. História do Futuro: ensino, pesquisa e divulgação científica, Rio de Janeiro, 21-25 de setembro de 2020.

PEREIRA, Edithe. O Museu Goeldi e a pesquisa arqueológica: um panorama dos últimos dezessete anos (1991-2008). Boletim do Museu Paraense Emílio Goeldi. Ciências Humanas, Pará, v. 4, n. 1, p. 171-190, jan./abr. de 2009.

SILVA FILHO, Eduardo Gomes da. Práticas inovadoras de ensino de história na Escola Agrotécnica da Universidade Federal de Roraima: novos desafios em tempos de COVID-19. Revista Manduarisawa, Manaus, v. 4, n. 2, p. 33-42, 2020.

URBAN, Ana Cláudia, LUPORINI, Tereza Jussara. Aprender e ensinar História nos anos iniciais e finais. São Paulo: Cortez, 2015.

\section{Documentos}

Nota Técnica 01/2020 PROGRAD/UEA.

Circular 01/2020 - Coordenação de Arqueologia.

Roteiro de Estudos - Arqueologia da Amazônia II (2020). 